\title{
Geothermal Energy as a Resource of Renewable Energy
}

\author{
${ }^{1}$ Othman M. Hussein Anssari, ${ }^{2}$ Layth Mohammed Abd Ali and ${ }^{3}$ Haider Ahmed Mohmmed \\ ${ }^{1}$ Information Technology Research and Development Center, University of Kufa, Najaf, Iraq \\ ${ }^{2}$ Quality Control Laboratory, University of Kufa, Najaf, Iraq \\ ${ }^{3}$ College of Engineering, University of Kufa, Najaf, Iraq
}

\begin{abstract}
This study includes design a condition geothermal system which is designed to take advantage of the heat emitted from the ground as a clean source. Almost widely available in all countries, system is based on the liquids materials in the ground using special pumps to get them, enable the soil to make balance between different temperatures for Summer and Winter and the exchange of heat with a ground. The change in temperature was measured for two rooms, one under normal conditions and the other using a geothermal system for 2 days in different months representing Winter and Summer.
\end{abstract}

Key words: Geothermal energy, power consumption, heat exchange, pumps, measured, temperatures

\section{INTRODUCTION}

A renewable energy source good alternative to fossil fuels, the natural high-temperature energy stored in the ground. This power is used mainly to generate electricity but it is too expensive. Volcanic activity with explosions, evaporation and associated gases are natural phenomena that indicate the warming of the Earth's interior.

\section{Geothermal energy advantages:}

- A valid energy source for many years to come (renewable energy)

- No pollution in the process of extraction, transformation and use (environmentally friendly energy)

- Available in large areas and in very large quantities

- Low energy production costs after the initial costs of operating the plant which are usually very high

- Higher yield of energy extracted compared to other renewable energy sources

- Clean and security system, no fires without fuel and odors (Florides and Kalogirou, 2005)

\section{MATERIALS AND METHODS}

Geothermal energy usage:Usage of thermal energy is divided into three main sections: electricity generation, direct uses and heat pumps. some possible uses are here:

- Electricity generation

- Direct uses such as
Agricultural uses:

- Heating of plastic houses for various agriculture and fish farming

- Heating chicken farms and any animal breeding sheds

- Drying of vegetables, fruit, fish and grain (Anonymous, 2014)

Industrial applications: Home heating and air conditioning, saltwater desalination, wood drying and processing, cooling in large refrigerators, gold mining, metal concentrate, papermaking and confectionery, dyeing cloth, milk pasteurization, dairy industry (Frota and Schiffer, 2006).

Health uses of physical therapy: Exploited hot water therapeutic "to stimulate blood circulation, muscle contraction and inflammation and treatment of respiratory problems, theumatism and skin diseases.

Tourism: Hot and cold springs increase the aesthetics of tourist areas.

Thermal pumps: An effective way to heat homes in the winter by transferring heat from the ground to the house, and cooling in summer "by transferring heat from the house to the ground (ASHRAE, 2008; Cengel, 2007).

The conversion of geothermal energy into electricity is done in three ways

Dry steam power station: This method was used in Italy in 1904 through, the extraction of natural water located in

Corresponding Author: Othman M. Hussein Anssari, Information Technology Research and Development Center, University of Kufa, Najaf, Iraq 


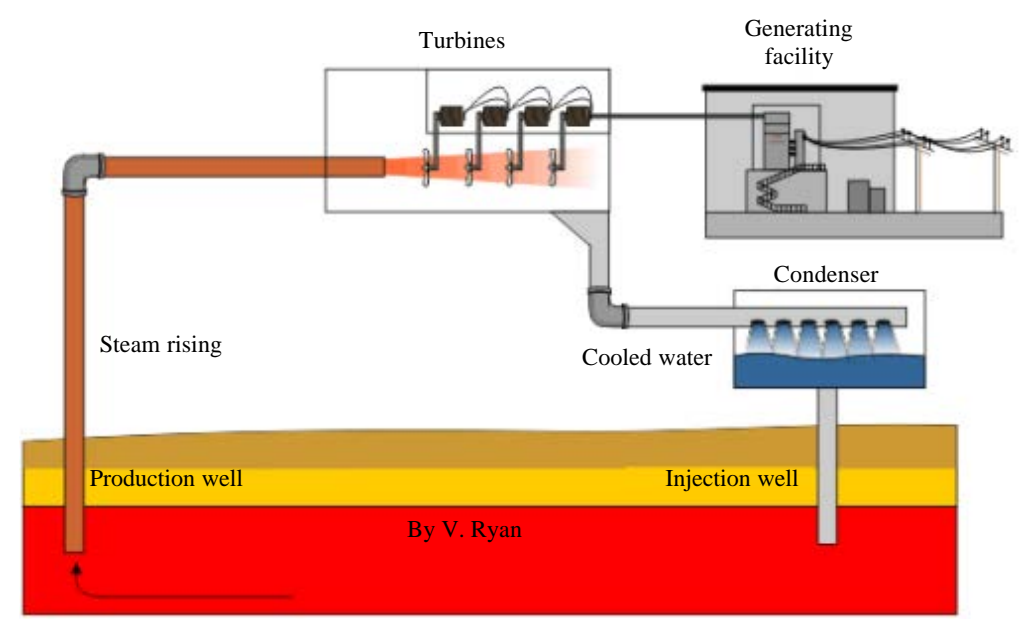

Fig. 1: Dry steam power station

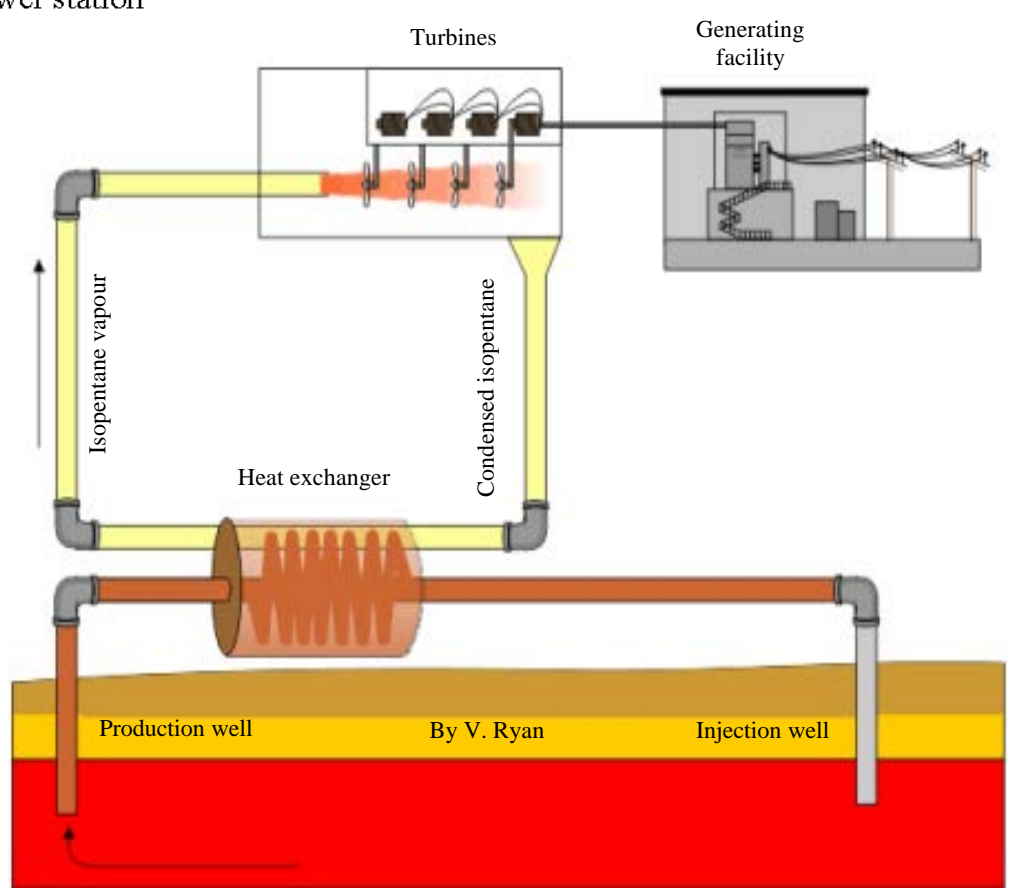

Fig. 2: Binary power cycle plant

the ground under the influence of heat and pressure high, water vapor in pipes destined to turbines to move the generators, leading to the production of electricity (Farret and Simoes, 2006) as shown in Fig. 1.

Binary power cycle plant: The liquids used under high pressure in the ground are used. A concentration of liquids in a small hole vessel leads to another vessel with moderate pressure. The liquids evaporate due to speed and high-pressure differentials. Turbine steam drives the movement of generators that produce electricity. To extract this type of steam must be drilled at deep depths as shown in Fig. 2.

Flash steam power station: These stations use underground liquids with a high boiling point that are pumped to the top where they heat the water with a normal boiling point in another tube that passes by the hot tub. The water heated by the high temperature of the liquid evaporates in the other tube. The steam drives the turbine of the electric generator that produces electricity and condenses back into the hot-tube conduits, moving in this way in continuous rotation as shown in Fig. 3. 


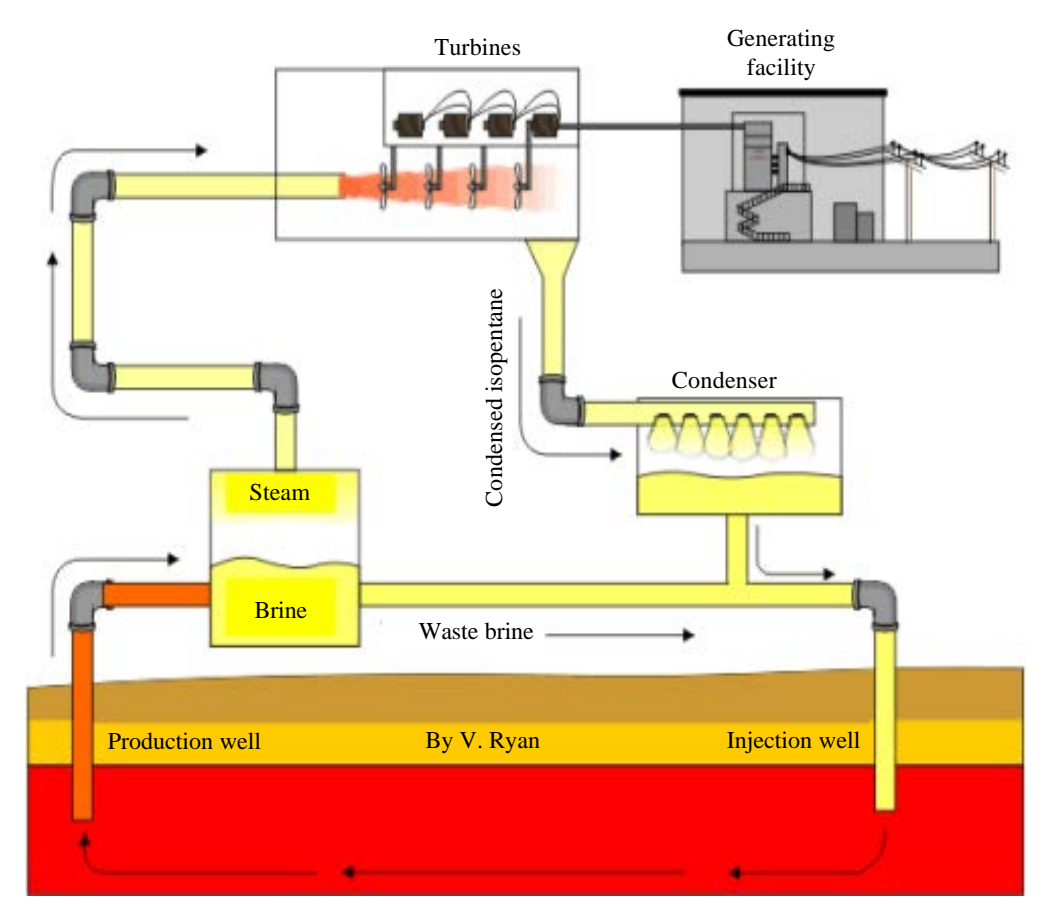

Fig. 3: Flash steam power station

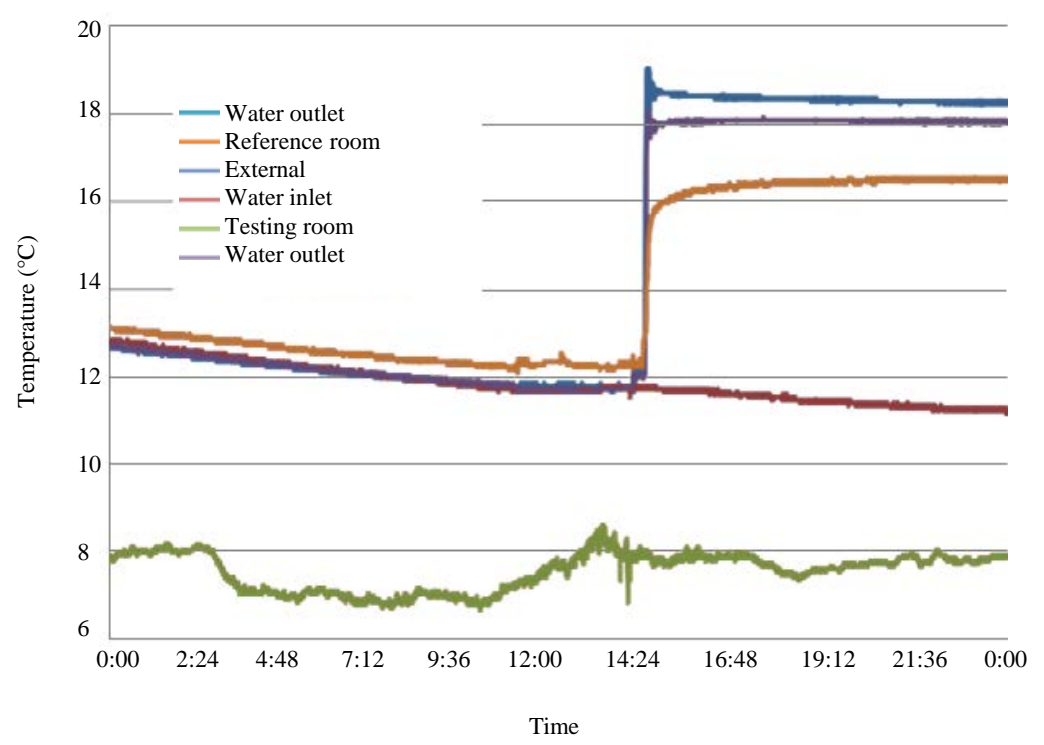

Fig. 4: System activated at (2:20 pm Winter July 10th 2017)

\section{RESULTS AND DISCUSSION}

Experimental results: Starting on 10th, July 2017 afternoon. Temperature control prototype testing room of geothermal air condition is activating (turning on) with an $8^{\circ} \mathrm{C}$ approximately external temperature. In Fig. 4 and $5 \mathrm{a}$ $19^{\circ} \mathrm{C}$ is the inlet water temperature and settled at 18.25 , $12.25^{\circ} \mathrm{C}$ is the outlet coolant water temperature and settled at $16.44^{\circ} \mathrm{C}$. At first without $\mathrm{HCC}$ control system is turned on, linked to a $\mathrm{DC}$ power source with only a consumption of $80 \mathrm{~W} / \mathrm{h}$.

Frontal presentation to sunlight, clouds shadow and wind causes an external temperature noise. Testing room temperature record (room 1) shown in Fig. 3 and 4, reference room (room 2) and the system is installed. Interestingly whenever the geothermal system 


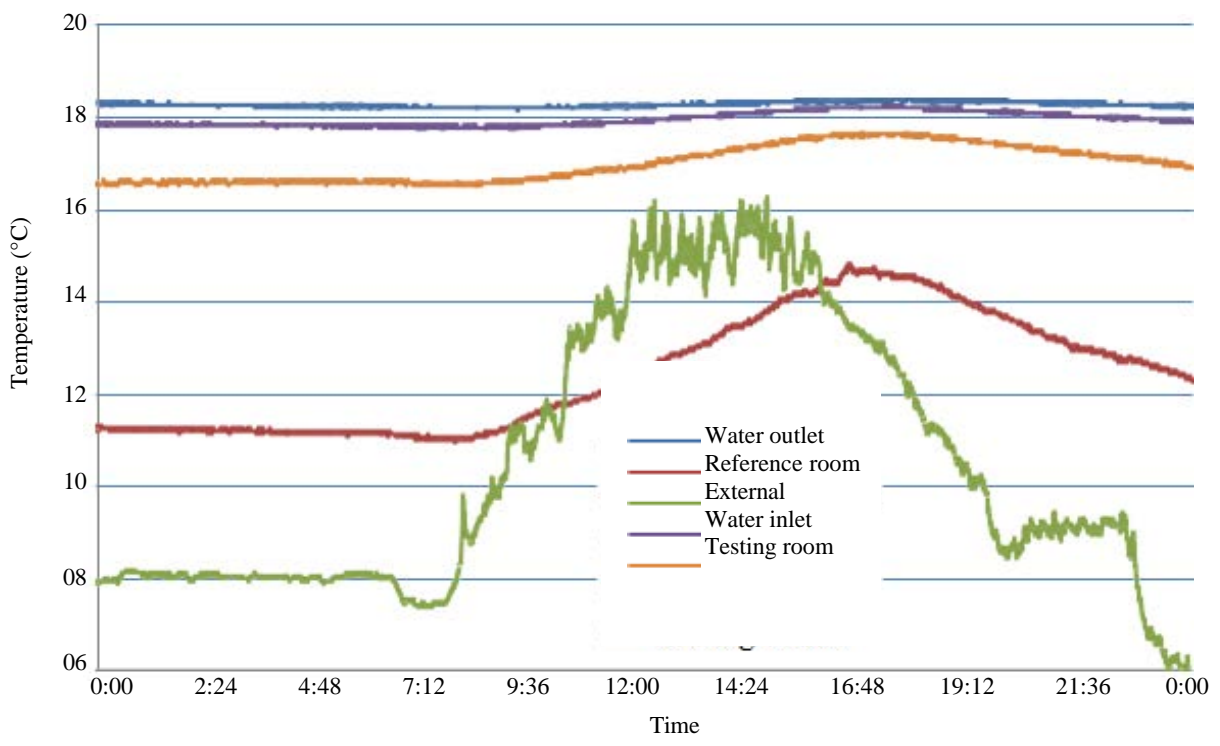

Fig. 5: Sensors temperatures at (Winter July 11 th 2017)

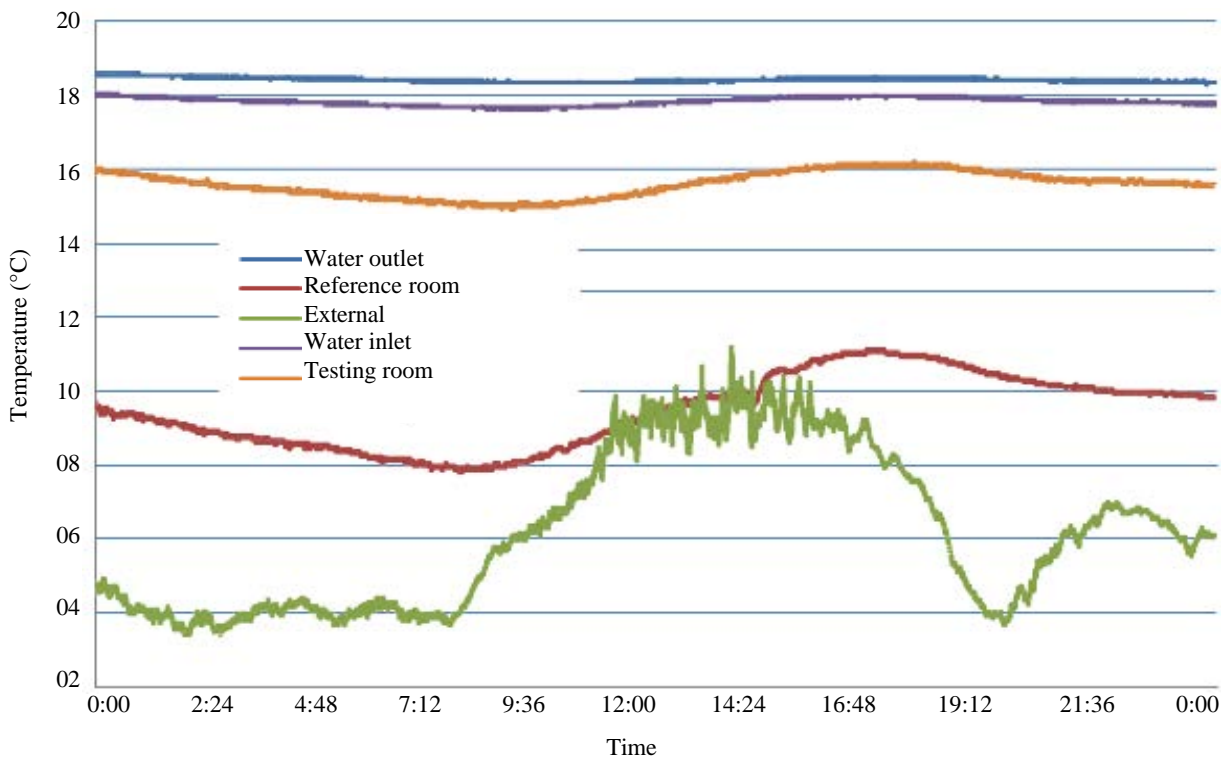

Fig. 6: Sensors temperatures at (Winter July 22th 2017)

is connecting, at $16^{\circ} \mathrm{C}$ (temperature stabilized) room temperature drops to equal the reference room temperature at $11.7^{\circ} \mathrm{C}$ with decreases in temperature of about $4.3^{\circ} \mathrm{C}$.

In Fig. 6 and 7 a sensors temperatures on the Jul 22th are shown in Fig. 5 and 6. Notice that testing room temperature is $15^{\circ} \mathrm{C}$ and reference room temperature is $7,875^{\circ} \mathrm{C}$ at $08: 10$ am with an average of $7,125^{\circ} \mathrm{C}$.

In Fig. 8 and 9 attention that temperature of the testing room is roughly constant even in colder ecological conditions. A difference of $5.5^{\circ} \mathrm{C}$ between the testing and reference rooms, testing room temperature drops to $17.5^{\circ} \mathrm{C}$. While the reference room drops to $12^{\circ} \mathrm{C}$.

Figure 10-12 illustrate the changes in power because the hill-climbing control setting extreme water pump running point. if HCC turned the water pump off, a temperature of inlet and outlet water drops to testing room temperature almost. The $70 \mathrm{~W}$ is the power spent from the complete system, showing that an appreciable decrease in electrical consuming. 


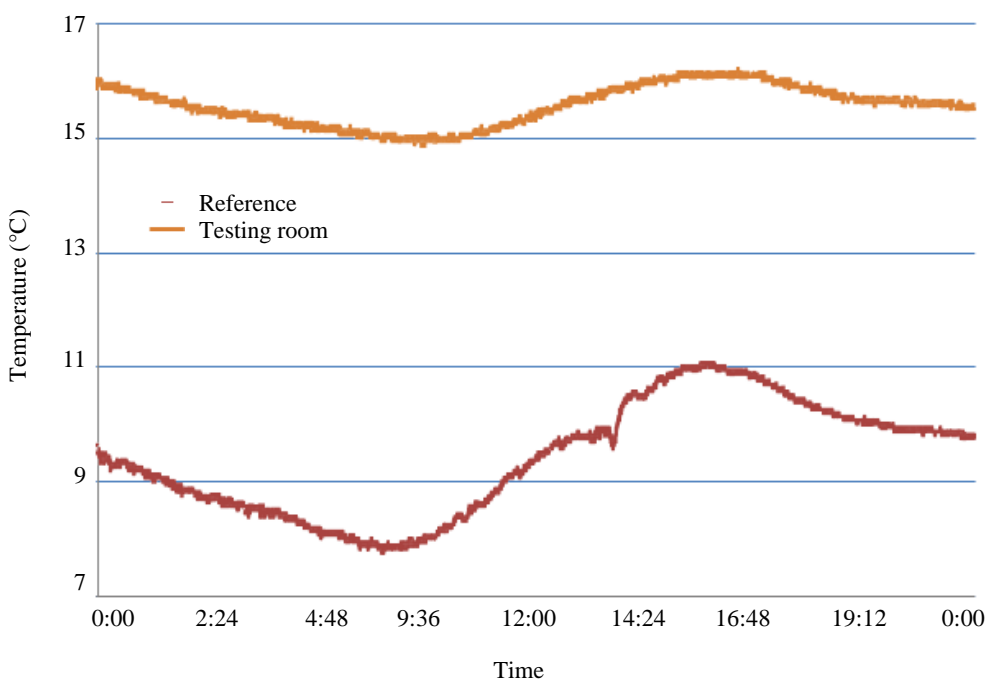

Fig. 7: Testing room and the reference room temperature at (Winter July 22th 2017)

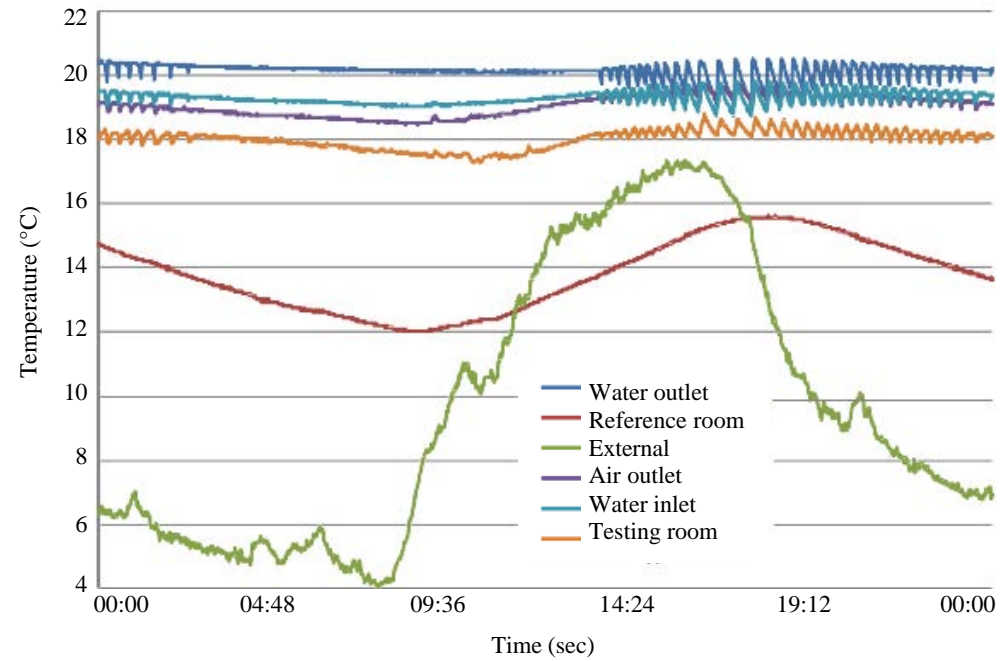

Fig. 8: Testing room and reference room temperature by using HCC control (Autumn June 9th, 2017)

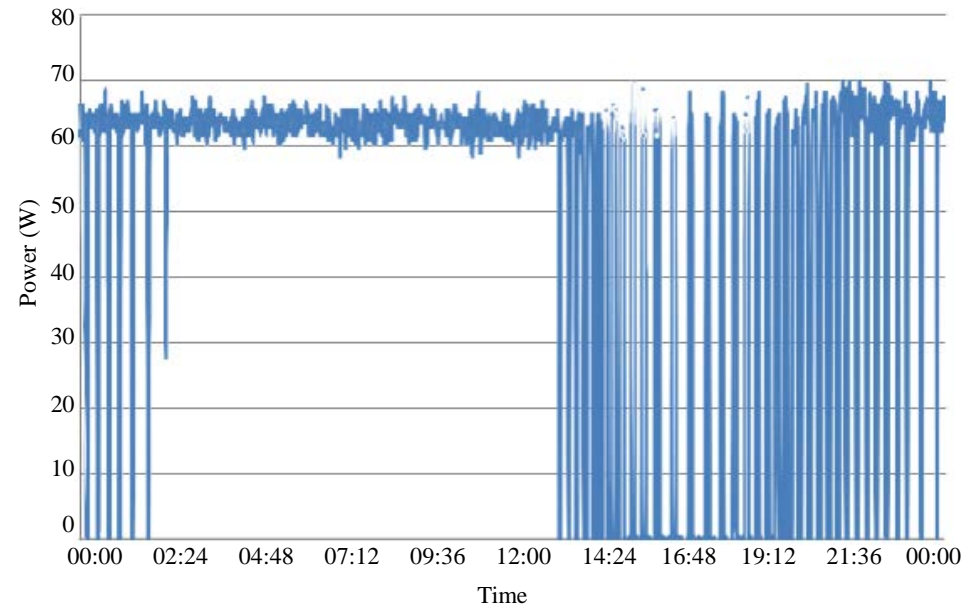

Fig. 9: Electrical consumption (June 9th, 2017) 


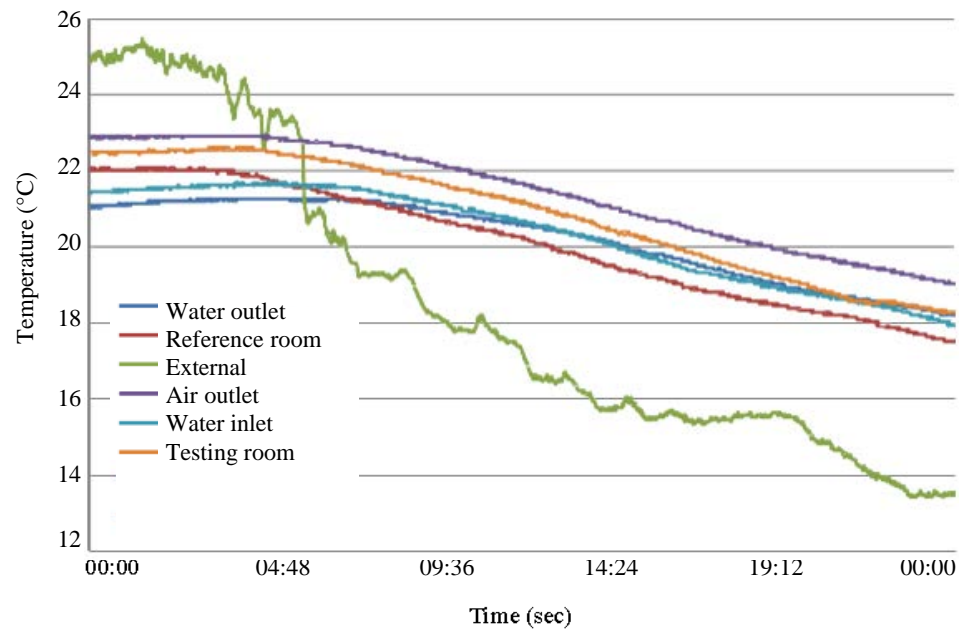

Fig. 10: Testing room and reference room temperature (Autumn June 13th, 2017)

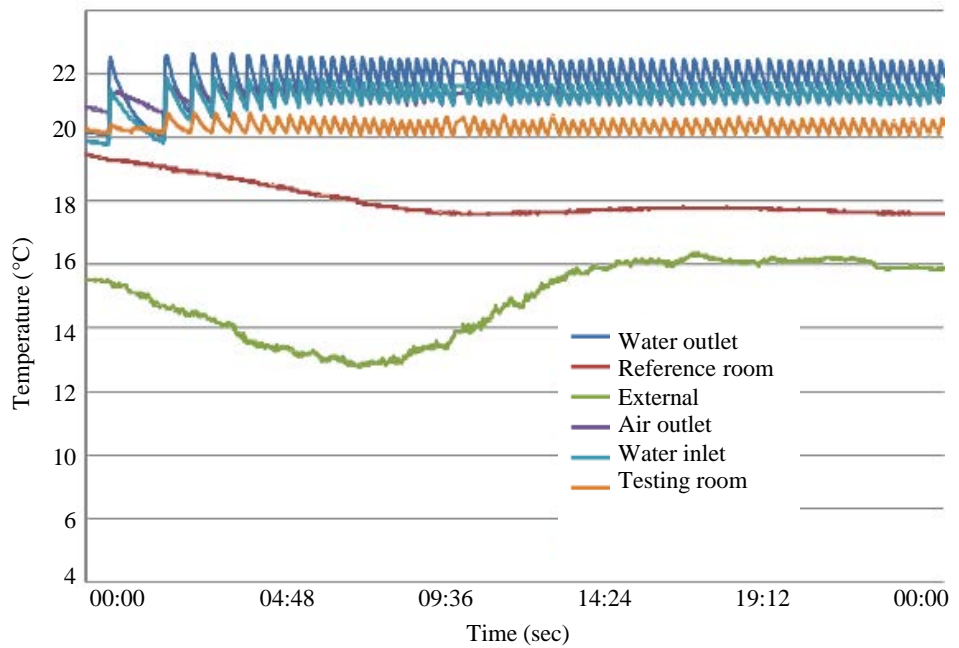

Fig. 11: Testing room and reference room temperature by using HCC control (Autumn June 14th 2017)

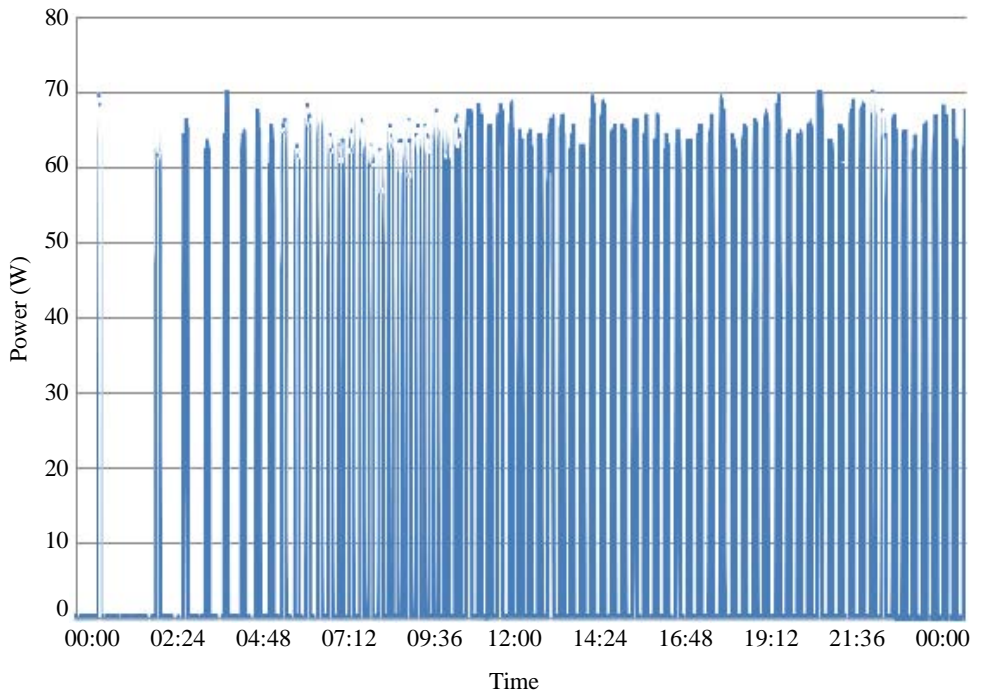

Fig. 12: Electrical consumption (June 14 2017) 


\section{CONCLUSION}

The research disappears a method of employ surface geothermal energy, contents a right dimension of the room heat and underground swapping. The installation in the tests depends on surface geothermal to decrease the expense with power by utilizing few establishments as well as low cost and suggest the best utilization of the conventional systems through heat swapping between underground and the room environment. The important buried pipes and constriction works were sensible volume utilizing just traditional landforms machines inhume them. In furthermore traditional geothermal energy doesn't need each fuel bank, just an inner clean refrigerant fluid throughout hosepipe.

\section{RECOMMENDATIONS}

To improve the system, some requirements are needed:

- Balance enhancement among buried pipes, room heat load, and heat swapping

- Heat insulation of outer walls enhancement

- Improve adjust speed of the fan and pump water

- Heat room coverage with plant life

\section{REFERENCES}

ASHRAE, 2008. Handbook of Fundamentals-HVAC Systems and Equipment. American Society of Heating Refrigeration and Air-conditioning Inc., New York, USA., ISBN:9781933742335, Pages: 888.

Anonymous, 2014. [Equipment and operation]. Geotics Solar Geothermal, Barcelona, Spain. (In Spanish) http://www.geotics.net/nweb/esp/03_02_a.php.

Cengel, Y.A., 2007. Heat and Mass Transfer: A Practical Approach. 3rd Edn., McGraw-Hill, New York, USA., ISBN:9780073250359, Pages: 901.

Farret, F.A. and M.G. Simoes, 2006. Integration of Alternative Sources of Energy. John Wiley \& Sons, Hoboken, New Jersey, USA., ISBN:9780471755616, Pages: 408.

Florides, G.A. and S.A. Kalogirou, 2005. Annual ground temperature measurements at various depths. Proceeddings of the 2005 8th International Rehva World Congress on Clima, October, 9-12, 2005, Lausanne, Switzerland, pp: 1-6.

Frota, A.B. and S.R. Schiffer, 2006. [Thermal Comfort Manual]. 2nd Edn., Livros Studio Nobel, Sao Paulo, Brazil, Pages: 243 (In Portuguese). 